\title{
Conducting the Needs Assessment \#3: Educator Motivations, Barriers, and Objections ${ }^{1}$
}

\author{
Matt Benge ${ }^{2}$
}

\section{Abstract}

The third publication in the Conducting the Needs Assessment series outlines a range of motivations, barriers, and common objections Extension educators and other service providers may have pertaining to needs assessments. It is not an easy task to conduct a needs assessment (Witkin \& Altschuld, 1995), yet there are many motives for implementing one. Strategies for increasing educator motivation and removing barriers and objections to conducting a needs assessment are discussed in this publication. For a complete list of the publications in this series, refer to the overview of the Conducting the Needs Assessment series in Appendix A.

\section{Introduction}

Extension educators are often tasked with a myriad of responsibilities, such as developing educational programs, assessing programs for impact, fundraising, recruiting volunteers, and marketing (Rasmussen, 1989; Seevers et al., 1997). One of the most fundamental acts an Extension educator can do is understand the needs of their community; educators and service providers cannot craft the right programs for their respective communities without knowing their true needs (Seevers et al., 1997). Understanding a community's needs, as well as identifying barriers to understanding a community's needs, can aid educators and administrators to increase the likelihood a needs assessment is completed prior to new educational or service initiatives taking place.

\section{Motivations for Needs Assessments}

Program development theory is founded upon the assumption that educators want what is best for their community (Seevers et al., 1997). Educators and service providers are charged to provide educational programs and services that help decrease their community's needs gap (Seevers et al., 1997). However, their attention can become diverted from this task for a myriad of reasons, such as being too busy with preexisting programming, focusing on activities rather than true educational programs, and experiencing job burnout or fatigue. Educators and service providers must stay focused on the larger picture of creating programs and services that are best for their community. There are many reasons for an educator or service provider to stay or become motivated to conduct a needs assessment.

To reach audiences in most need of the service. Educational programs and services should be created for and conducted in delivery formats and locations where community members who need them the most can access them (Batsche et al., 1999; Witkin \& Altschuld, 1995). Educators and service providers can stay motivated to conduct a needs assessment because it can ensure their program and services are reaching the audiences within their community

1. This document is AEC724, one of a series of the Department of Agricultural Education and Communication, UF/IFAS Extension. Original publication date March 2021. Visit the EDIS website at https://edis.ifas.ufl.edu for the currently supported version of this publication.

2. Matt Benge, assistant professor, Extension education, Department of Agricultural Education and Communication, UF/IFAS Extension, Gainesville FL 32611.

The Institute of Food and Agricultural Sciences (IFAS) is an Equal Opportunity Institution authorized to provide research, educational information and other services

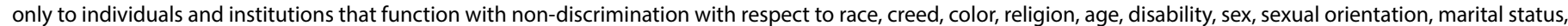

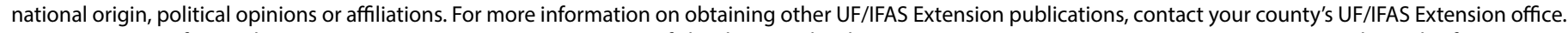
U.S. Department of Agriculture, UF/IFAS Extension Service, University of Florida, IFAS, Florida A \& M University Cooperative Extension Program, and Boards of County Commissioners Cooperating. Nick T. Place, dean for UF/IFAS Extension. 
that are in most need of the activities. Additionally, needs assessments can also be used to segment audiences into homogenous groups with similar needs (Monaghan et al., 2014), thereby reaching more audiences within their community.

Opinion leaders can champion your needs assessment. Opinion leaders are defined as members within a community whose beliefs, words, and actions hold much influence and power (Rogers \& Cartano, 1962). Opinion leaders often serve on boards and advisory committees because they have the ability to impact change, and they often play a large role in providing vocal and financial support for outreach programs. Opinion leaders can play a large role in the needs assessment process, such as being a key preexisting source of data or serving on a needs assessment focus group. Opinion leaders and stakeholders who are involved in the needs assessment process can champion not only the needs assessment but also any new educational or service initiatives that stem from the results.

\section{To achieve a greater return on educational program} outcomes. Educators and service providers who conduct a needs assessment create a foundation for achieving a greater return on investment from their programs and services. Community audiences can be targeted more effectively through a needs assessment, whereby "learning is more likely to lead to change in practice when [a] needs assessment has been conducted" (Grant, 2001, para 5).

To increase accountability to stakeholders and policy makers. Stakeholders and policy makers often ask tough questions about educational programs and initiatives within their community (Donaldson \& Franck, n.d.; Swinton et al., 2020). Educators and service providers can use the needs assessment to maintain or justify programmatic efforts by answering the "Why are you doing this?" question that many stakeholders and policy makers ask. Educators can use needs assessment data to help inform opinion leaders (a) prior to a program being conducted to create buy-in, (b) during a program to share preliminary results, or (c) at the conclusion of a program to demonstrate the program's effectiveness.

To apply and increase program support. It is no secret that educational programs and services cost money! However, educators and service providers need more program support than money to offer programs to their community (Etling \& Maloney, 1995; Witkin \& Altschuld, 1995). Program support is anything that one needs to support a program, such as money (funding), facilities, staff, equipment, supplies, transportation, and marketing.
Educators can use a needs assessment to determine where program support should be allocated, as well as if more program support is needed based on the needs assessment data.

An investment. Another motivation for educators and service providers is to consider the needs assessment as an investment (Jones, 2017). An investment in the financial world is considered "an asset or item acquired with the goal of generating income or appreciation" (Chen, 2020, para 1). The needs assessment is an investment because it helps the educator or service provider generate greater program outcomes and impacts within their community.

Needs change over time. A community's needs can change over time (Etling \& Maloney, 1995) for many reasons, such as shifts in demographics, an increase in population, or changes in socioeconomic status. If educators and service providers have been successful in decreasing the needs gap within their community, it might be that their community needs different programs or services, and therefore a new needs assessment might be necessary to identify them.

To create opportunities for collaborations. Educators and organizations that collaborate have the "potential to increase programmatic outcomes" (Jones et al., 2020, para 1). Educators and service providers can use the results of a needs assessment to create partnerships with other educators and organizations that have similar needs. On the flip side, the needs assessment might indicate that the needs might be different from the current collaborator's needs, thereby signaling that collaboration might not be effective or a good use of available resources.

\section{Removing Educator Barriers and Objections to Conducting Needs Assessments}

Educators and service providers may have reservations about conducting a needs assessment. Though these barriers and objectives can deter someone from conducting a needs assessment, there are many strategies educators and administrators can use to help remove them.

"I already know what the needs in the community are." Oftentimes educators and service providers have specific knowledge of their community that is useful to providing insight into the need(s) (Witkin \& Altschuld, 1995). However, professionals sometimes use only this information to create programs and services rather than conducting a needs assessment. Before creating anything new, it is 
important to take a step back and gather existing data to ensure that what the educator thinks the needs are align with the priority needs of a community. Seek counsel from advisory committees and opinion leaders to check if the knowledge of the need is what others see too.

"I do not have the time." Many educators and service providers can become very busy with their job and frequently explain that they are too inundated with their job responsibilities to conduct a needs assessment (Russell et al., 2019). In addition, new employees often want to "hit the ground running" and start programming right off the bat before understanding what their community's needs are. The program development model (Seevers et al., 1997) paints a clear picture, explaining that conducting a needs assessment is essential and a priority. One of the best ways to combat the "lack of time" is to make time by scheduling it in a calendar in advance, which dedicates time to work on a needs assessment.

"I do not know how to assess needs." Educators and service providers have specific knowledge and content expertise in the area they are teaching. However, many do not have expertise in program development, such as conducting a needs assessment (Davis et al., 2012). The Conducting a Needs Assessment series is here to help educators and service providers with planning and conducting a needs assessment. Additionally, check with professional associations to request needs assessment workshops. Educators and service providers may have a program development specialist who can help plan and conduct a needs assessment. A professional consultant could be hired to conduct a needs assessment if the educator is unable to do so on their own.

“People are oversurveyed." It is true that clientele report that they are asked to complete too many surveys (Smith, 2020; Witkin \& Altschuld, 1995). However, there are many alternate methods to conducting a needs assessment that do not involve a survey. The Conducting a Needs Assessment series provide common needs assessment tools and techniques that can be used instead of surveys to assess the needs of a community.

\section{Conclusion}

This third publication in the Conducting the Needs Assessment series outlined a range of motivations, barriers, and common objections Extension educators and other service providers may have pertaining to needs assessments. We provided strategies to assist both the educator and administrator to both increase motivation and remove barriers to conducting the needs assessment. For a brief overview of each publication in the series, see Appendix A.

\section{References}

Batsche, C., Hernandez, M., \& Montenegro, M. C. (1999). Community needs assessment with Hispanic, Spanish-monolingual residents. Evaluation and Program Planning, 22(1), 13-20. https://doi.org/10.1016/ S0149-7189(98)00036-6

Chen, J. (2020). Investment. https://www.investopedia.com/ terms/i/investment.asp

Davis, D., Lambur, M., Lindstrom, J., \& Lippke, L. (2012). NAEPSDP and eXtension national Extension training needs survey. Unpublished raw data. National Association of Extension Program and Staff Development Professionals and eXtension.

Donaldson, J. L., \& Franck, K. L. (n.d.). Needs assessment guidebook for Extension professionals. PB 1839. University of Tennessee Extension, Institute of Agriculture. https://extension.tennessee.edu/publications/Documents/PB1839.pdf

Etling, A., \& Maloney, T. (1995). Needs assessment for Extension agents and other nonformal educators. https:// files.eric.ed.gov/fulltext/ED388774.pdf

Grant, J. (2001). Learning needs assessment: Assessing the need. $B M J$, 324(156). https://doi.org/10.1136/ bmj.324.7330.156

Jones, J. A., Simonne, E., \& Banis, L. (2020). Increasing collaboration between Extension and community-based nonprofits: The quick chats workshop. Journal of Extension, 58(1), Article v58-1iw2. https://tigerprints.clemson.edu/joe/ vol58/iss1/12/

Jones, R. (2017). 5 good reasons to do a training needs assessment. https://www.trainingfolks.com/ blog/5-good-reasons-to-do-a-training-needs-assessment

Monaghan, P., Warner, L., Telg, R., \& Irani, T. (2014). Improving Extension program development using audience segmentation. EDIS, 2014(6). https://edis.ifas.ufl.edu/wc188

Rasmussen, W. D. (1989). Taking the university to the people: Seventy-five years of cooperative extension. Iowa State University Press 
Rogers, E. M., \& Cartano, D. G. (1962). Methods of measuring opinion leadership. The Public Opinion Quarterly, 26(3), 435-441. https://www.jstor.org/stable/2747233

Russell, M. B., Attoh, P., Chase T., Gong, T., Kim, J., \& Liggans, G. L. (2019). Burnout and extension educators: Where we are and implications for future research. Journal of Human Sciences \& Extension, 7(1), 195-211. https:// www.jhseonline.com/article/view/817/710

Seevers, B., Graham, D., Gamon, J., \& Conklin, N. (1997). Education through cooperative Extension. Delmar Publications.

Smith, J. (2020, July 10). People are over-surveyed, and not in the way you might suspect. https://supportinglines. com/2020/07/10/people-over-surveyed/

Swington, J. J., Killian, T., \& Wray, P. (2020). Importance of adding objective data to stakeholder data in needs assessments. Journal of Extension, 58(3), Article v58-3tt7. https:// tigerprints.clemson.edu/joe/vol58/iss3/1/

Witkin, B. R., \& Altschuld, J. W. (1995). Planning and conducting needs assessments: A practical guide. Sage Publications.

\section{Appendix A: Conducting the Needs Assessment Series Overview}

Conducting the Needs Assessment \#1: Introduction

General summary of needs assessments, including what a needs assessment is, the different phases, and tools to conduct a needs assessment.

Conducting the Needs Assessment \#2: Using Needs Assessments in Extension Programming

Overview of using needs assessments as part of the Extension program planning process.

Conducting the Needs Assessment \#3: Motivations, Barriers and Objections

Information about the motivations, barriers, and objections to conducting needs assessments for Extension professionals and service providers.

Conducting the Needs Assessment \#4: Audience Motivations, Barriers, and Objections

Information about the motivations, barriers, and objections that clientele and communities may have for participating or buying-in to a needs assessment.
Conducting the Needs Assessment \#5: Phase 1-Pre-assessment

Introduction to the Pre-assessment phase of conducting a needs assessment, including defining the purpose, management, identifying existing information, and determining the appropriate methods.

\section{Conducting the Needs Assessment \#6: Phase}

\section{2-Assessment}

Introduction to the Assessment phase of conducting a needs assessment, including gathering and analyzing all data.

\section{Conducting the Needs Assessment \#7: Phase}

3-Post-assessment

Introduction to the Post-assessment phase of conducting a needs assessment, including setting priorities, considering solutions, communicating results, and evaluating the needs assessment.

\section{Conducting the Needs Assessment \#8: The Borich Model}

Overview of using the Borich Model to conduct a needs assessment.

\section{Conducting the Needs Assessment \#9: The Nominal Group Technique}

Overview of using the Nominal Group Technique to conduct a needs assessment.

\section{Conducting the Needs Assessment \#10: The Delphi Technique}

Overview of using the Delphi Technique to conduct a needs assessment.

\section{Conducting the Needs Assessment \#11: The Causal Analy- sis Technique}

Overview of using the Causal Analysis Technique to conduct a needs assessment. 